\title{
Depression and Anxiety among Parents of Children with Cystic Fibrosis Related to the Children's Health Related Quality of Life
}

\author{
Agneta Bergsten Brucefors' ${ }^{1}$, Jacek Hochwälder ${ }^{2}$, Jessica Sjövall1, Lena Hjelte ${ }^{1}$ \\ ${ }^{1}$ Stockholm CF Centre, Karolinska University Hospital Huddinge, Karolinska Institutet, Stockholm, Sweden \\ ${ }^{2}$ Department of Psychology, Mälardalen University, Eskilstuna, Sweden \\ Email: agneta.bergsten-brucefors@karolinska.se
}

Received 9 March 2015; accepted 17 May 2015; published 20 May 2015

Copyright (C) 2015 by authors and Scientific Research Publishing Inc.

This work is licensed under the Creative Commons Attribution International License (CC BY). http://creativecommons.org/licenses/by/4.0/

(c) (7) Open Access

\begin{abstract}
The aim was to examine depression and anxiety among parents of children with Cystic Fibrosis and the association between the parents' symptoms and the child's quality of life as rated by the parents. Parents completed HADS (Hospital Anxiety and Depression Scale), and CES-D (Center of Epidemiologic Studies Depression Scale), and assessed the children's quality of life with CFQ-R (Cystic Fibrosis Questionnaire-Revised). Anxiety amongst the parents was higher than the general population $(\mathrm{m}=6.55, \mathrm{SD}=3.54, \mathrm{p}<0.001)$. The level of depression does not differ from that of the general population. Mothers showed more anxiety symptoms than fathers $(p<0.001)$. Gender differences were not significant for depression symptoms. There is a strong association between the fathers' self-rated depression and their rating of their child's health. Both children and parents should be paid attention to in order to identify mental ill-health and take measures in good time.
\end{abstract}

\section{Keywords}

Cystic Fibrosis, Depression, Anxiety, Quality of Life, Parents, Children

\section{Introduction}

Cystic fibrosis (CF) is one of the most common life-shortening, hereditary illnesses amongst western populations. Today there are a total of about six hundred patients in Sweden with CF and every year about twenty children are born with the illness [1]. The diagnosis is usually established during childhood and for a long time CF was regarded as a childhood illness as the patients seldom reached adulthood. As treatment improves the number of gown-up patients has increased and life expectancy amongst Swedish patients with CF is now close to 50 
year [2].

CF is caused by a defect in the CF transmembrane conductance regulator, with secondary effects on many cellular functions. It leads to chronic pulmonary infection, pancreatic insufficiency and abnormal levels of electrolytes in sweat. The lung manifestations cause most of the CF related morbidity and mortality. There is no cure for the illness. The treatment is symptomatic, comprehensive and time-consuming for the patients. It consists of, amongst other things, respiratory physiotherapy and physical training, medicinal treatment, pancreatic enzyme supplementation, nutritional treatment as well as psychosocial support. The patients also require regular antibiotic treatment due to chronic growth of bacteria in the lower airways. Even if patients with CF are living much longer than in the past they still have chronic pulmonary infections and other medical complications related to their disease, including diabetes, intestinal obstruction, cirrhosis, hemoptysis and pneumothorax.

Chronic illness in children not only affects the child, but also involves all the family members. As the CFdiagnosis is often established when the children are small, it is the parents who initially react to it [3]. The illness necessitates life-long and extensive treatment. It is also the parents who have the ultimate responsibility to ensure that home treatment is carried out regularly and that the child keeps appointments at the CF-unit. Helping the child with motivation and encouragement is also the parents' task.

Many studies have been carried out with the aim of examining anxiety, depression and quality of life in parents of children with CF [4]-[7]. They show that a greater proportion of parents of children with CF have high ratings on anxiety and depression scales compared with parents of healthy children. The more anxiety and depression amongst those caring for the child, the lower the self-reported quality of life in the children is. Depression in the parents can also be associated with the child's compliance to treatment. An overview of research on children of depressed parents emphasizes that these children show increased prevalence of general adjustment problems [8] and a meta-analysis of studies on parenting stress among caregivers of children with chronic illness states that this issue is an important target for intervention [9].

In general the parents of children with CF are not more depressed or anxious than other adults. The crucial difference is due rather to the parents' characteristics. It is the parents who blame themselves for their child's illness, who do not set up goals for the child and who believe that things will go badly for the child in the future, who can be in the risk zone for anxiety and depression [10]. It is of interest to study the situation among the Swedish parents of CF-children in order to improve the care of the children if necessary.

Anxiety and depression symptoms amongst parents of children with cystic fibrosis in contact with Stockholm's CF-centre are in focus of this investigation. The correlation between the parents' anxiety and depression symptoms and the children's quality of life as rated by the parents is also studied. Important questions are: How large a proportion of the parents show anxiety and depression symptoms? Is there a correlation between the parents' anxiety and depression symptoms and the children's quality of life as rated by the parents? Are there differences between mothers and fathers in these aspects?

\section{Method}

\subsection{Subjects}

A multinational study conducted by professor Alexandra Quittner University of Florida, started in 2008 with the aim of examining depression, and anxiety amongst patients with CF as well as amongst parents of children with CF [11]. This is a one-centre study from Stockholm's CF-centre connected to the multinational study. The study was approved by the Regional Ethic Committee at the Karolinska Institute (Dnr 2007/1266-31). Parents and youth aged 15 to 18 were informed about the study and asked if they wanted to participate. They all left a written answer. The number of parents of CF-children belonging to the Stockholm CF-centre was one hundred and seventy-four parents of eighty-eight children aged up to 18 years. Some parents have more than one child with CF (see Table 1).

The response frequency of the parents was 64\% (109 individuals). There were in all sixty-one mothers and forty-eight fathers and they were parents of seventy children.

The parents' ages, civil status, education and employment status are shown in Table 2.

Age, civil status and educational level do not differ from the corresponding percentage in the general population in Sweden [12].

The majority of the parents were in employment. One hundred and one $(92.7 \%)$ parents worked full or parttime. The proportion of adults in employment in the whole country in 2008 was $76 \%$. 
Table 1. Distribution of parents who answered the questionnaires, according to the age of the child.

\begin{tabular}{ccccc}
\hline Age of child & All parents & Only mother & Only father & Both mother and father \\
\hline $0-5 \mathrm{y}$ & 34 & 2 & & 32 \\
$6-11 \mathrm{y}$ & 38 & 6 & 3 & 32 \\
$12-14 \mathrm{y}$ & 15 & 5 & 3 & 10 \\
$15-17 \mathrm{y}$ & 22 & 3 & 3 & 90 \\
$0-17 \mathrm{y}$ & 109 & 16 & 36 \\
\hline
\end{tabular}

Table 2. Age, civil status, education and employment status of the parents. All parents and mothers and fathers separately.

\begin{tabular}{|c|c|c|c|}
\hline Variable & All parents $(\mathrm{N}=109)$ & Mothers (N = 61) & Fathers $(\mathrm{N}=48)$ \\
\hline Age (years) & $24-56$ & $24-52$ & $24-56$ \\
\hline M (SD) & $39.5(6.8)$ & $38.8(6.7)$ & $40.4(7.0)$ \\
\hline \multicolumn{4}{|l|}{ Civil status (\%) } \\
\hline Single/never married & 1.8 & 1.6 & 2.1 \\
\hline Married & 53.2 & 50.8 & 56.3 \\
\hline Divorced & 13.8 & 16.4 & 10.4 \\
\hline Separated & 0.9 & 1.6 & - \\
\hline Remarried & 1.8 & 1.6 & 2.1 \\
\hline With a partner & 28.4 & 27.9 & 29.2 \\
\hline \multicolumn{4}{|l|}{ Education (\%) (highest grade) } \\
\hline Some high school or less & 1.8 & 1.6 & 2.1 \\
\hline High school diploma & 35.8 & 32.8 & 39.6 \\
\hline Vocational school & 14.7 & 14.8 & 14.6 \\
\hline Some college & 16.5 & 18.0 & 14.6 \\
\hline College degree & 30.3 & 32.8 & 27.1 \\
\hline Professional or graduate degree & 0.9 & - & 2.1 \\
\hline \multicolumn{4}{|l|}{ Employment status (\%) } \\
\hline Seeking work & 3.7 & 4.9 & 2.1 \\
\hline $\begin{array}{l}\text { Working full or part time (either outside the home or at } \\
\text { a home-based business) }\end{array}$ & 92.7 & 91.8 & 93.8 \\
\hline Fulltime homemaker & 1.8 & 1.6 & 2.1 \\
\hline Not working due to my health & 1.8 & 1.6 & 2.1 \\
\hline
\end{tabular}

\subsection{Procedure}

The patients and parents filled in the questionnaires at an ordinary visit at the centre. The parents completed the three questionnaires that were intended to measure anxiety and depression (HADS and CES-D) as well as their assessment of the child's quality of life (CFQ-R).

\subsection{Measures}

\subsubsection{Health}

The children's health was here described in terms of lung capacity measured at the annual check-up. Lung func- 
tion in percent of predicted was calculated from the reference values presented by Solymar et al. [13]. Forced Expiratory Volume per second in percentages of expected value (FEV1\%) was used. For a person with CF (as well as for a healthy individual) a lung function of about $90 \%$ of predicted or more is regarded as normal [14]. Data about FEV1\% are missing for fourteen children in the age group 0 - 5 years, as it is not possible to measure lung capacity with any precision in the smallest children.

\subsubsection{Hospital Anxiety and Depression Scale (HADS)}

HADS is an easy to administer, self-assessment form intended to measure anxiety and depression symptoms respectively [15]. HADS comprises 14 statement divided into two subscales: Anxiety and Depression. The symptoms are rated on a four point Likert scale from 0 - 3 points giving a maximum of 21 points per subscale. Individuals scoring 7 points or less on one of the subscales probably do not experience anxiety or depression of clinical relevance. 8 points is a cut-off value. Scores between 8 and 10 are regarded as risk values. Individuals, who score 11 points or more, probably experience anxiety or depression of clinical significance. According to Swedish norms the average for HADS totals 8.53 (range $0-42$ ). The average for the subscale HADS-anxiety is 4.55p (range 0 - 21) and for HADS-depression 3.98 (range 0 - 21) [16].

\subsubsection{Center of Epidemiologic Studies Depression Scale (CES-D)}

CES-D is a self-assessment form that is used to measure depression symptoms during the past week in adults [17]. The scale comprises 20 questions intended to examine both somatic and cognitive depression symptoms. Each item is rated on a four point scale from $0=$ seldom or no part of the time (less than a day) to $3=$ most of the time or the whole time (5 - 7 days). A total score is calculated by adding together the rated items. The higher the score the greater is the number of depressive symptoms. A result of 16 points is regarded as the clinical cut-off value for depressive symptoms and has also been used in the analysis of the material in question.

\subsubsection{Cystic Fibrosis Questionnaire-Revised (CFQ-R)}

CFQ-R is a Health Related Quality of Life instrument (HRQoL) specially developed for the CF population [18]. The parent version of the CFQ- $R$ is a proxy-rating questionnaire with 44 items and 11 dimensions where parents report on their child's HRQoL. The dimensions are: physical, emotion, vitality, school, body, eat, treat, health, respiration, digest, and weight.

Max-value for each dimension is 100 (most positive, "healthy") and the result is given in shares of 100 (\%). This was filled in by thirty-two mothers and twenty-one fathers for thirty-five children age 6 - $14 \mathrm{y}$.

\section{Statistical Analysis}

The statistical analyses were made in SPSS, version 15. Descriptive statistics (M, SD), t-values as well as calculations of the Pearson product-moment correlation coefficient were carried out.

\section{Results}

\subsection{Health Status of the CF-Children}

The average for the children's FEV1\% is 89.14 per cent predicted which is to consider as normal. In the analyzed sample there was one child with CF in the age group 0 - 17 years that had CF-related diabetes. Two children had had hemoptysis (coughing blood) or pneumothorax (air in the pleura). Forty-five (64\%) children had at one time (or more) received antibiotics intravenously. None of the children had been prescribed antidepressants.

\subsection{Anxiety and Depression Symptoms amongst the Parents}

Table 3 shows the means and the SD of HADS and CES-D for mothers and fathers.

The mean for HADS Anxiety amongst parents of children with CF in the age group $0-17$ years is significantly higher than the average for a Swedish population sample $(\mathrm{z}=5.6, \mathrm{p}<0.001)$. Forty-two $(38.5 \%)$ parents reported anxiety symptoms above the cut-off value, fourteen (12.8\%) at a clinical level. The results are higher than that expected amongst the general Swedish population, where $12 \%-20 \%$ is at risk of suffering from an anxiety disorder at least once during their lifetime [19].

The average for HADS Depression in the same group does not differ significantly from the general population 
Table 3. Means and SD for HADSA, HADSD and CES-D. Mothers and fathers and mothers and fathers together.

\begin{tabular}{|c|c|c|c|c|c|c|c|}
\hline \multirow{2}{*}{$\begin{array}{c}\text { Anxiety and } \\
\text { depression }\end{array}$} & \multicolumn{2}{|c|}{ All parents } & \multicolumn{2}{|c|}{ Mothers } & \multicolumn{2}{|c|}{ Fathers } & \multirow{2}{*}{$\begin{array}{l}\text { Diff mothers/ } \\
\text { fathers }\end{array}$} \\
\hline & M & SD & $\mathbf{M}$ & SD & $\mathbf{M}$ & SD & \\
\hline \multirow[t]{2}{*}{ HADSA } & 6.55 & 3.54 & 7.51 & 3.77 & 5.33 & 2.81 & $\mathrm{t}_{109}=3.33$ \\
\hline & & & & & & & $\mathrm{p}<0.001$ \\
\hline HADSD & 3.77 & 3.02 & 3.79 & 3.23 & 3.75 & 2.78 & NS \\
\hline \multirow[t]{2}{*}{ CES-D } & 10.48 & 9.12 & 12.64 & 9.76 & 7.73 & 7.47 & $\mathrm{t}_{109}=2.88$ \\
\hline & & & & & & & $\mathrm{p}<0.005$ \\
\hline
\end{tabular}

$(z=0.39, p>0.05)$. The results from the HADS Depression scale show that fifteen (13.7\%) parents rated depression symptoms above the cut-off value and $3.7 \%$ at clinical level. The results show that the parents do not differ from the general population with regard to depression symptoms.

On the CES-D twenty-four (22\%) parents were over the cut-off value (>15p). The probability of developing depression during their lifetime, up to 99 years, was $22.5 \%$ for men and $30.7 \%$ for women in Sweden during the period 1972-1997 [20]. The CF parents did not show any deviation from the general population during this period.

The results regarding anxiety symptoms differed significantly between mothers and fathers. Thirty-two (52.5\%) mothers reported anxiety symptoms within or above the cut-off values (19.7\% at clinical level). The corresponding figures for fathers were ten (20.8\%) individuals within or above the cut-off values $(4.1 \%$ at clinical level). The gender difference was not significant for depression symptoms. Nine (14.7\%) mothers and six (12.5\%) fathers reported symptoms within or above the cut-off values. Only one (2.1\%) father rated the values at a clinical level. Amongst the mothers there were six (9.8\%) within the cut-off values and three (4.9\%) rated results at a clinical level.

For the CES-D nine-teen (31.1\%) mothers reported a result above the cut-off value (>15p) whereas amongst the fathers there were five (10.4\%) who scored above.

According to the HADS Depression results there is no significant difference between fathers and mothers. HADS Anxiety shows that significantly more mothers than fathers show clear anxiety symptoms. CES-D that takes into consideration both somatic and cognitive depression symptoms also shows that significantly more mothers that fathers have clinically defined symptoms.

\subsection{The Association between the Parents' Anxiety and Depression Symptoms and the Children's Health as Rated by Their Parents}

The correlation between the parents' anxiety and depression symptoms (HADS and CES) and the children's health rated by the parents is shown in Table 4. The questionnaires were filled in by thirty-two mothers and twenty-one fathers.

The table shows that there is a significant correlation between the fathers' mental health and their ratings of their children's health. Depression symptoms (HADSD) and a more general measure of depression symptoms (CES) appear to be the strongest. The strongest correlation is with Respiration. The mothers do not show any correlation between anxiety and depression symptoms and the children's health but between Respiration and the more general measure (CES) of depression.

There is a certain correlation between the parents' anxiety and depression symptoms and the children's quality of life as rated by the parents. The correlation appears to be strongest with the fathers' depression symptoms. The mothers, on the other hand, show almost no correlation at all.

\section{Discussion}

According to the results the parents rated higher with regard to anxiety symptoms than the general Swedish population. Hardly $40 \%$ of all parents of children with CF rated symptoms within or higher than the cut-off values (8p - 11p - 16p) and approximately 13\% have, according to the results, anxiety of clinical significance (>11p). 
Table 4. Correlation between the parent's anxiety and depression symptoms and the children's (age 6 - 14 y) health and quality of life as rated by their parents.

\begin{tabular}{|c|c|c|c|c|c|c|c|c|c|}
\hline \multirow[b]{2}{*}{ Variables } & \multicolumn{3}{|c|}{ All parents $(n=53)$} & \multicolumn{3}{|c|}{ Fathers $(n=21)$} & \multicolumn{3}{|c|}{ Mothers $(n=32)$} \\
\hline & HADSD & HADSA & CES & HADSD & HADSA & CES & HADSD & HADSA & CES \\
\hline FEV1\% & -0.16 & -0.13 & -0.08 & -0.30 & $-0.33^{*}$ & -0.21 & -0.07 & -0.02 & -0.01 \\
\hline Physical & $-0.27^{*}$ & -0.11 & -0.25 & $-0.63^{* *}$ & -0.29 & $-0.44^{*}$ & -0.15 & -0.07 & -0.20 \\
\hline Emotion & -0.09 & -0.20 & -0.03 & -0.36 & -0.07 & -0.11 & -0.11 & 0.02 & -0.32 \\
\hline Vitality & -0.19 & -0.02 & -0.23 & $-0.59^{* *}$ & -0.34 & -0.36 & 0.04 & 0.16 & -0.14 \\
\hline School & -0.26 & -0.10 & -0.17 & $-0.54^{* *}$ & -0.41 & -0.33 & -0.14 & 0.03 & -0.07 \\
\hline Eat & -0.20 & 0.08 & -0.12 & -0.34 & -0.03 & -0.19 & 0.03 & 0.11 & -0.07 \\
\hline Body & -0.14 & 0.05 & -0.21 & $-0.50^{*}$ & -0.25 & $-0.56^{* *}$ & 0.09 & 0.20 & 0.01 \\
\hline Treat & -0.14 & -0.17 & $-0.29^{*}$ & -0.42 & $-0.52^{*}$ & $-0.59^{* *}$ & -0.03 & -0.05 & -0.16 \\
\hline Health & $-0.28^{*}$ & -0.19 & $-0.35^{* *}$ & $-0.56^{* *}$ & -0.27 & $-0.53^{*}$ & -0.13 & -0.15 & -0.24 \\
\hline Resp & $-0.36^{* *}$ & $-0.36^{* *}$ & $-0.56^{* *}$ & $-0.44^{*}$ & $-0.63^{* *}$ & $-0.81^{* *}$ & -0.31 & -0.25 & $-0.41^{*}$ \\
\hline Digest & -0.26 & -0.23 & $-0.36^{* *}$ & -0.29 & $-0.46^{*}$ & $-0.54^{*}$ & -0.24 & -0.15 & -0.27 \\
\hline Weight & -0.20 & -0.08 & -0.23 & $-0.45^{*}$ & -0.02 & -0.32 & -0.05 & -0.12 & -0.18 \\
\hline
\end{tabular}

The parents do not, appear to run any greater risk of becoming depressed compared to other Swedes. Approximately $14 \%$ rate depression symptoms within or above the cut-off values and approximately $4 \%$ have depression of clinical significance.

Compared with international results parents of children with CF in Stockholm are at a corresponding level with regard to anxiety symptoms [21], but depression appears to be less common compared with parents of children with CF in Europe [22] [23]. The results thus reflect that, amongst parents of children with CF, 0 - 17 years, belonging to Stockholm CF Centre, anxiety dominates, i.e. it is worry rather than depression that is the primary consequence of living with a child that has a chronic illness necessitating life-long treatment. Why Swedish parents react differently than European parents is unclear. Apart from personal characteristics and culture it may be speculated that different countries have varying success in treating CF, have different ways of conveying hope and that healthcare services may have various ways of meeting parents in crisis.

Parents who are within or above the cut-off value on the anxiety scale reported chiefly worrying thoughts as well as fear, restlessness and strain. Those with values of clinical significance generally report that they are troubled by the above symptoms to a greater degree than those that are within the cut-off values. In addition there is a tendency to respond with "often" to the question about suffering from feelings of panic compared with those who were within the cut-off values who in turn, to a greater extent, answered, "sometimes". Panic feelings are a type of undifferentiated anxiety that can be particularly difficult to control. Those with a clinical level on the depression scale seem above all to be troubled by joylessness regarding both the present and the future to a greater extent than other parents. These are also feelings that are relatively undifferentiated and therefore difficult to manage. Parents who suffer from panic feelings or joylessness are in general in need of psychological help. It is essential to pay attention to these risks within CF care and to offer psychological support to the parents. Psychological support of the parents is also important for the children's well-being [8].

One result of this study is a clear gender difference amongst the parents' ratings on the anxiety scale. The results show that mothers rated anxiety higher than fathers. The difference is significant. Every other mother rated anxiety within or above the cut-off values, and about $20 \%$ have anxiety of clinical significance. Corresponding figures for fathers were $20 \%$ within the cut-off values and approximately $4 \%$ at clinical level. The statistics show that women in general experience anxiety to a significantly greater extent than men. According to the latest Public Health Report [24] from the National Board of Health and Welfare approximately 15\% men and 25\% women report anxiety. The results in this sub-study can be assumed to reflect this difference. 
With regard to depression symptoms, excluding physical symptoms, that could have a connection with a somatic condition (HADS Depression), there are no significant gender differences. If, on the other hand, questions concerning both somatic and cognitive depression symptoms are included, it appears that mothers rate depression symptoms significantly higher than fathers. This is an observation requiring further research.

On examination of the correlation between anxiety and depression symptoms amongst the parents and the children's health as rated by their parents, another gender difference was found. Whereas the mothers showed barely any correlation, the fathers showed strong correlation with most of the self-rated variables regarding the children's health. The correlation is smaller with regard to objective measures of the child's health (FEV1\%). It is most pronounced with regard to depression symptoms (HADS) as well as the more general assessment of anxiety and depression (CES).

The mothers' anxiety symptoms do not appear to influence their assessment of the children's health. It is not observable in the data whether the fathers gave the children's health a low rating because they themselves felt low or whether they felt low because they considered the children to have poor health. This difference between mothers and fathers may indicate an underlying need of more support amongst the fathers and that they are more exposed to how they perceive the child's health status than are the mothers. Another underlying cause may be that mothers are generally more worried about their children than fathers and therefore are not further affected by how they perceive the child's health.

A limitation with the current sub-study is that comparisons have not been made with parents other than the general population. This means that the latter includes both parents of children in different age groups and persons without children. The results have not been followed up qualitatively which hampers the opportunity to make a deeper analysis. In contrast to many international studies, however, the current sub-study has a relatively even gender distribution amongst the parents and this is a strength. This has facilitated an insight into the difference between mothers and fathers' way of managing chronic illness in their child/children.

\section{Conclusion}

Future studies should also include qualitative measures. From the above mentioned results, it is also important to pay attention to both children with CF and their parents at annual check-ups in order to identify mental ill-health and take measures in good time and also to be sensitive to the need for supportive interventions.

\section{References}

[1] Socialstyrelsen (2010) Ovanliga Diagnoser (Unusual Diagnoses). Cystisk Fibros.

[2] De Monestrol, I., Klint, Å., Sparén, P. and Hjelte, L. (2010) Age at Diagnosis and Disease. Progression of Cystic Fibrosis in an Area without Newborn Screening. In: Paediatric and Perinatal Epidemiology, Blackwell Publishing Ltd., Hoboken, 1-8.

[3] Götz, I. and Götz, M. (2000) Cystic Fibrosis: Psychological Issues. Paediatric Respiratory Reviews, 1, 121-127. http://dx.doi.org/10.1053/prrv.2000.0033

[4] Driscoll, K.A., Johnson, S.B., Barker, D., Quittner, A.L., Deeb, L.C., Geller, D.E., Gondor, M. and Silverstein, J.H. (2010) Risk Factors Associated with Depressive Symptoms in Caregivers of Children with Type 1 Diabetes or Cystic Fibrosis. Journal of Pediaticr Psychology, 35, 814-822. http://dx.doi.org/10.1093/jpepsy/jsp138

[5] Hodgkinson, R. and Lester, H. (2002) Stresses and Coping Strategies of Mothers Living with a Child with Cystic Fibrosis: Implications for Nursing Professionals. Journal of Advanced Nursing, 39, 377-383.

http://dx.doi.org/10.1046/j.1365-2648.2002.02299.x

[6] Quittner, A.L., Barker, D.H., Snell, C., Grimley, M.E., Marciel, K. and Cruz, I. (2008) Prevalence and Impact of Depression in Cystic Fibrosis. Current Opinion in Pulmonary Medicine, 14, 582-588. http://dx.doi.org/10.1097/MCP.0b013e3283121cf1

[7] Ylimas, O., Sogut, A., Gulle, S., Can, D., Ertan, P. and Yuksel, H. (2008) Sleep Quality and Depression-Anxiety in Mothers of Children with Two Chronic Respiratory Diseases: Asthma and Cystic Fibrosis. Journal of Cystic Fibrosis, 7, 495-500. http://dx.doi.org/10.1016/j.jcf.2008.05.002

[8] Downey, G. and Coyne, J.C. (1990) Children of Depressed Parents: An Integrative Review. Psychological Bulletin, 108, 50-76. http://dx.doi.org/10.1037/0033-2909.108.1.50

[9] Cousino, M.K. and Hazen, R.A. (2013) Parenting Stress among Caregivers of Children with Chronic Illness. A Systematic Review. Journal of Pediatric Psychology, 38, 809-828. http://dx.doi.org/10.1093/jpepsy/jst049 
[10] Wong, M.G. and Heriot, S.A. (2008) Parents of Children with Cystic Fibrosis: How They Hope, Cope, and Despair. Child: Care Health Development, 34, 344-354. http://dx.doi.org/10.1111/j.1365-2214.2007.00804.x

[11] Cruz, I., Marciel, K.K., Quittner, A.L. and Schechter, M.S. (2009) Anxiety and Depression in Cystic Fibrosis. Seminars in Respiratory and Critical Care Medicine, 30, 569-578. http://dx.doi.org/10.1055/s-0029-1238915

[12] Statistical Database. www.scb.se/statistikdatabasen

[13] Solymar, L., Aronsson, P.H., Bake, B. and Bjure, J. (1980) Nitrogen Single Breath Test, Flow-Volume Curves and Spirometry in Healthy Children, 7 - 18 Years of Age. European Journal of Respiratory Diseases, 61, 275-286.

[14] Hankinson, J.L., Odencrantz, J.R. and Fedan, K.B. (1999) Spirometric Reference Values from a Sample of the General U.S. Population. American Journal of Respiratory and Critical Care Medicine, 159, 179-187. http://dx.doi.org/10.1164/ajrccm.159.1.9712108

[15] Zigmond, A.S. and Snaith, R.P. (1983) The Hospital Anxiety and Depression Scale. Acta Psychiatrica Scandinavica, 67, 361-370. http://dx.doi.org/10.1111/j.1600-0447.1983.tb09716.x

[16] Lisspers, J., Nygren, A. and Söderman, E. (1997) Hospital Anxiety and Depression Scale (HAD): Some Psychometric Data for a Swedish Sample. Acta Psychiatrica Scandinavica, 96, 281-286. http://dx.doi.org/10.1111/j.1600-0447.1997.tb10164.x

[17] Radloff, L. (1997) The CES-D Scale: A Self-Report Depression Scale for Research in the General Population. Applied Psychological Measurement, 1, 386-401.

[18] Quittner, A.L., Buu, A., Messer, M.A., Modi, A.C. and Watrous, W. (2005) Development and Validation of the Cystic Fibrosis Questionnaire in the United States: A Health-Related Quality-of-Life Measure for Cystic Fibrosis. Chest, 128, 1-13. http://dx.doi.org/10.1378/chest.128.4.2347

[19] SBU (2005) Behandling av ångestsyndrom, volym 1. En systematisk litteraturöversikt (Treatment of Anxiety Syndromes, Volume 1. A Systematic Literature Overview). Statens beredning för medicinsk utvärdering (SBU), Stockholm, Swedish Council on Health Technology Assessment.

[20] Mattisson, C., Bogren, M., Nettelbladt, P., Munk-Jörgensen, P. and Bhugra, D. (2005) First Incidence Depression in the Lundby Study: A Comparison of the Two Time Periods 1947-1972 and 1972-1997. Journal of Affective Disorders, 87, 151-160. http://dx.doi.org/10.1016/j.jad.2005.04.002

[21] Besier, T., Born, A., Henrich, G., Hinz, A., Quittner, A.L. and Goldbeck, L. (2011) Anxiety, Depression and Life Satisfaction in Parents Caring for Children with Cystic Fibrosis. Pediatric Pulmonology, 46, 672-682. http://dx.doi.org/10.1002/ppul.21423

[22] Driscoll, K.A., Montag-Leifling, K., Acton, J.D. and Modi, A.C. (2009) Relations between Depressive and Anxious Symptoms and Quality of Life in Caregivers of Children with Cystic Fibrosis. Pediatric Pulmonology, 44, 784-792. http://dx.doi.org/10.1002/ppul.21057

[23] Quittner, A.L., Barker, D.H., Geller, D., Butt, S. and Gondor, M. (2007) Effects of Maternal Depression on Electronically Monitored Enzyme Adherence and Changes in Weight for Children with CF. Journal of Cystic Fibrosis, 6, S78. http://dx.doi.org/10.1016/S1569-1993(07)60292-6

[24] Folkhälsorapporten (2009) The National Public Health Report. http://www.socialstyrelsen.se 